\title{
Effects of coarse sand dosage on the physic-mechanical behavior of sand concrete
}

\author{
Saloua Melais, Meriem Fakhreddine Bouali, Ahmed Melaikia, Amine Amirat \\ Department of Civil Engineering, Faculty of Sciences \& Technology, University of Mobamad Cherif Messaadia, Souk Ahras, \\ 41000, Algeria \\ s.melais@univ-soukahras.d\%. \\ m.bouali@univ-soukahras.dz.b.meriemfakhreddine@gmail.com,bttp://orcid.org/0000-0002-6986-980X \\ bamdi.10mel@gmail.com,amine.amirat1623@gmail.com
}

\begin{abstract}
The development and research of a new formulation of concrete integrating natural resources such as sands (from dunes and/or quarries) as well as waste from steel factories in the form of granulated slag from blast furnaces lead to the development of new sand concretes for which the improvement of specific properties will lead to a search for an agreement between production cost and performance. The objective of this research is to study the influence of the dosage of the size of the largest aggregate on the workability of sand concretes as well as on the compressive strength at 7 days, 14 days and 28 days. Five types of concrete are made by substituting aggregates (dune sand and quarry sand) with each other and with different percentages $(100 \%, 75 \%, 50 \%, 25 \%$ and $0 \%)$. The results show that the workability of fresh concrete is considerably influenced by the nature of the sand; the richer the sand in coarse elements, the fineness modulus increases and the more handling improves. In the hardened state, the results show that optimization of the compressive strength is achieved when a good homogeneity of the concrete is achieved and when a large percentage of coarse sand is mixed with a small percentage of fine sand.
\end{abstract}

KEYwORDS. Sand concrete; Extended granular; Workability; Mechanical behavior.

\section{OPEN $\bigcirc$ ACCESS}

Citation: Melais, S. Bouali, M.F., Melaikia, A. Amirat, A., Effects of coarse sand dosage on the physic-mechanical behavior of sand concrete, Frattura ed Integrità Strutturale, 56 (2021) 151-159.

Received: 09.03 .2021

Accepted: 13.03.2021

Published: 01.04.2021

Copyright: (C) 2021 This is an open access article under the terms of the CC-BY 4.0, which permits unrestricted use, distribution, and reproduction in any medium, provided the original author and source are credited.

\section{INTRODUCTION}

I $\mathrm{n}$ a country like Algeria rich in sand of different granulometry (more than two million $\mathrm{km}^{2}$ with a very vast desert) and poor in stony materials, reinforced concrete constructions become a little expensive, the modification of local resources in terms of materials can at least partially solve the problem of the growing demand for housing [1]. Sand concretes (henceforth SC) are a new line of building materials that can replace traditional concrete for economic reasons and for its specific qualities [2-5]. 
In addition to its richness in sand, Algeria has an "El-Hadjar" iron and steel complex which produces enormous quantities of waste and by-products each year, in particular crushed slag and granulated slag. These quantities are estimated at 500,000 tons per year. These slags can be used in the manufacture of concrete and mortars in the form of sand, gravel and fine additions or mineral additions. Granulated slag as a mineral or fines additions or as a cement substitute is widely used in the formulation of different types of mortars, concrete and innovative concretes.

Several countries around the world have started using BS (Sand Concrete). In France, a national program called Sablocrete has been launched. This project has largely introduced and developed the technique of sand concrete [2]. Russia, a rich country in sand, but poor in gravel and massive rocks, has not ceased since 1941 to use BS in various fields of civil engineering [2, 6]. Several studies and research have been carried out in Algeria in order to develop this material [7,8]. In Tunisia, research has led to very encouraging results $[9,10]$ with a view to the use of sand concrete compacted into bodies of pavement, this material remains ignored in the building industry.

Sand concretes can hence be used for the prefabrication of low or non-bearing elements, or structural elements. It can be poured in place for the construction of horizontal or vertical elements [2]. This material also presents a good alternative for sprayed concrete which eliminates complex formwork and allows various shapes [11].

Several studies have been conducted in order to minimize the drawbacks of sand concrete and improve mechanical performance by correcting the granular extent, the type and dosage of addition fines, addition of admixtures, addition of fibers, etc.

The aim of this essentially experimental research is to study the influence of the dosage of the size of the largest aggregate on the workability of sand concretes as well as on the compressive strength. The main purpose of this work is also to find the optimal mixture possible between dune sand and quarry sand in order to obtain satisfactory mechanical characteristics and plastic sand concrete.

Many works have been carried out for the use of dune sand as a substitute for quarry sand. $[12,13]$ and they have shown that the incorporation of desert sand into the crushing sand improves the mechanical strengths, as long as the percentage of replaced dune sand is less than $15 \%$, an excess of fines will be observed beyond this percentage. On the other hand $[12,14]$, they have also shown that the best mechanical strengths were obtained for a substitution of $30 \%$ river sand and $70 \%$ of crushed sand. This was explained by the decrease in the volume of voids following the incorporation of river sand. Thus [15], it has been found that the best resistances are obtained with the mixture of coarse quarry sand - fine siliceous sand with the same volume which show the best granular spread with a $23 \%$ cladding, then quarry sand and crystallized slag sand with gains of $15 \%$ and $12 \%$ respectively. This was explained by the improvement in the compactness of sand concretes and consequently the increase in density and mechanical resistance thanks to the good grain size distribution of quarry sand and the mixture of silica sand - quarry sand, which is confirmed by [16], that showed that the behavior of concrete is influenced by the type of sand, the rate of fines and the shape of sand particles. Other researchers have shown that aggregates with their shapes have a significant influence on the rheological properties of cement mortars as well as on the physical properties [17].

It is in this context that our study falls under the use of two types of fine and coarse sand, the aim of which is to obtain results that can improve the state of knowledge of the mechanical performance of Sand Concrete. Finally, the comparison of the experimental results of compressive strengths and workability between the different formulations will complete this study.

\section{MATERIALS AND FORMULATION OF STUDY CONCRETES}

\section{Materials}

o formulate a sand concrete one must respect the standard NFP 18-101 which limits the size of the largest grains of sand to $5 \mathrm{~mm}$. The selected constituents are represented in Fig. 1 and are as follows:

Aggregates: two types of sand are used: dune sand (DS) with a granular extent of 0/1.25 with a fineness modulus of 2.1, quarry sand (QS) with a granular extent of $1.25 / 5$ and a fineness modulus from 3.22. The mean values of the sand equivalents show that the study sands are slightly clayey with an acceptable cleanliness for concrete of current quality and shrinkage is not particularly feared.

\section{Cement}

The cement used is a Composite Portland Cement (CPJ-CEM II / A 42.5) (NF EN197-1) from a single delivery from the cement plant (GICA) in the town of CHLEF. The chemical and mineralogical compositions are given in Tabs. 1 and 2 respectively. 


\begin{tabular}{cccccccccc}
\hline Elements & $\mathrm{CaO}$ & $\mathrm{SiO}_{2}$ & $\mathrm{Al}_{2} \mathrm{O}_{3}$ & P.A.F & $\mathrm{Fe}_{2} \mathrm{O}_{3}$ & $\mathrm{SO}^{3}$ & $\mathrm{MgO}$ & $\mathrm{Residue}$ \\
Content $(\%)$ & 61.69 & 20.34 & 5.37 & 5.03 & 3.00 & 2.20 & 1.80 & 1.12 \\
\hline
\end{tabular}

Table 1: Chemical composition of cement.

\begin{tabular}{ccccc}
\hline Elements & $\mathrm{C}_{3} \mathrm{~S}$ & $\mathrm{C}_{2} \mathrm{~S}$ & $\mathrm{C}_{3} \mathrm{~A}$ & $\mathrm{C}_{4} \mathrm{AF}$ \\
Content (\%) & 58.3 & 14.6 & 8.7 & 11.26 \\
\hline
\end{tabular}

Table 2: Mineralogical composition of the used cement.

Filler

The used additive fines are granulated slag fillers obtained by grinding the by-products of the iron and steel industry with a granular extent of $<80 \mu \mathrm{m}$. (Standard XP P 18-540). The chemical composition is shown in Tab. 3.

\begin{tabular}{cccccccc}
\hline Elements & $\mathrm{CaO}$ & $\mathrm{SiO}_{2}$ & $\mathrm{Al}_{2} \mathrm{O}_{3}$ & $\mathrm{Fe}_{2} \mathrm{O}_{3}$ & $\mathrm{~S}$ & $\mathrm{MgO}$ & $\mathrm{MnO}$ \\
Content $(\%)$ & 43.0 & 40.8 & 5.2 & 0.50 & 0.8 & 6.4 & 3.0 \\
\hline
\end{tabular}

Table 3: Chemical composition of slag.

\section{Superplasticizer}

SIKA VISCOCRETE TEMPO 12 is the super plasticizer chosen for the formulation of sand concrete. It has a liquid form and a light brown color. It complies with standard NF EN 934-2. Its properties are shown in Tab. 4.

\begin{tabular}{|c|c|c|c|c|}
\hline P.H & Density & $\begin{array}{l}\text { Content in } \\
\mathrm{Na}_{2} \mathrm{O}\end{array}$ & $\begin{array}{l}\text { Content in ions } \\
\mathrm{Cl}^{-}\end{array}$ & Dosage \\
\hline $6 \pm 1$ & $1.06 \pm 0.01$ & $\leq 1 \%$ & $\leq 0.1 \%$ & $\begin{array}{c}0.2 \text { to } 3 \% \text { of } \\
\text { diluent weight } \\
\text { or that of } \\
\text { cement }\end{array}$ \\
\hline
\end{tabular}

Table 4: Property of the SIKA VISCOCRETE TEMPO 12.

\section{Mixing water}

According to NFP 18-303, drinking water is always suitable. The used water is that of the tap.

\section{Formulation of study concretes}

The retained method for the sand concrete formulation will be a theoretical approach of SABLOCRETE formulation adjusted experimentally. The different formulations of study sand concretes are distinct in terms of the dosage of the two mixtures of dune sand (fine) and quarry sand (coarse), the aim of which is to seek the optimal type of concrete that gives the best physico-mechanical characteristics.: five types of sand concrete are tested: SC1 $100 \%$ dune sand, $0 \%$ quarry sand; SC2 75\% dune sand, $25 \%$ quarry sand; SC3 50\% dune sand, 50\% quarry sand; SC4 25\% dune sand, $75 \%$ quarry sand); SC5 0\% dune sand, 100\% quarry sand. All the retained formulations are given in Tab. 5. 


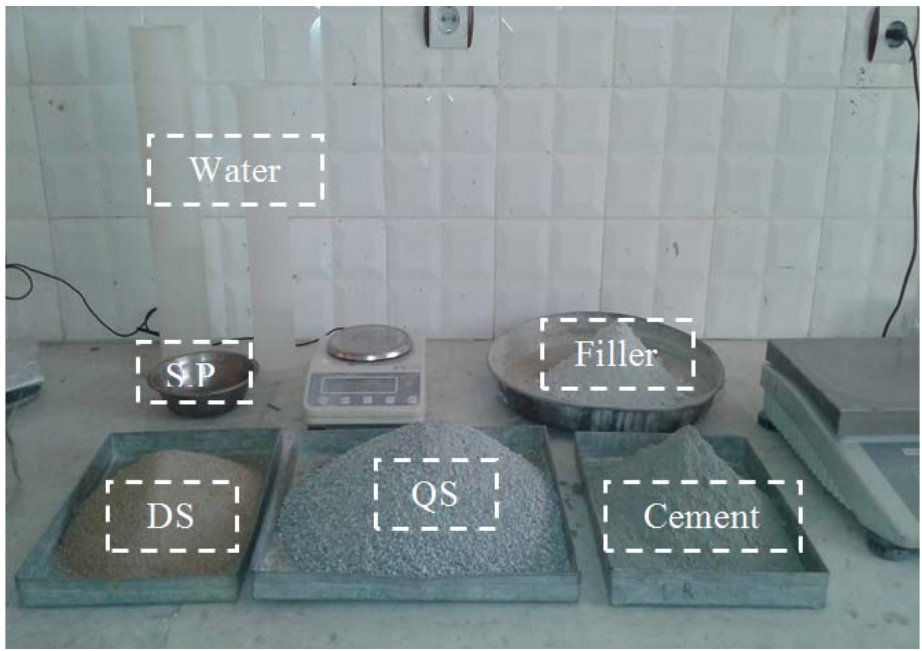

Figure 1: Constituents of the study Sand Concrete.

\begin{tabular}{ccccccc}
\hline Concrete References & $\begin{array}{c}\text { Dune Sand } \\
\text { (DS) }(\mathrm{kg})\end{array}$ & $\begin{array}{c}\text { Quarry } \\
\text { Sand }(\mathrm{QS}) \\
(\mathrm{kg})\end{array}$ & $\begin{array}{c}\text { Cement } \\
(\mathrm{kg})\end{array}$ & $\begin{array}{c}\text { Filler } \\
(\mathrm{kg})\end{array}$ & $\begin{array}{c}\text { Water } \\
\text { (Liters) }\end{array}$ & $\begin{array}{c}\text { Super } \\
\text { Plasticizer } \\
2 \%(\mathrm{~kg})\end{array}$ \\
SC1 & 1472.8 & 0 & 397.92 & 195.32 & 207.5 & 11.86 \\
SC2 & 1183 & 408 & 362.49 & 145.13 & 182.33 & 10.15 \\
SC3 & 789 & 816 & 362.49 & 145.13 & 182.33 & 10.15 \\
SC4 & 394.5 & 1224 & 362.49 & 145.13 & 182.33 & 10.15 \\
SC5 & 0 & 1932 & 362.49 & 145.13 & 182.33 & 10.15 \\
\hline
\end{tabular}

Table 5: Formulation and properties of sand concretes.

\section{EXPERIMENTAL PROCEDURE}

$\mathrm{T}$

he mixing of the concrete is carried out according to the NF P18-404 standard in a concrete mixer with a capacity of 30 liters, with a total mixing time of 5 minutes. The vibration of the concrete is carried out on a vibrating table for $30+30$ s. After storing the molds in air for 24 hours, the test pieces are stored in saturated humidity $(\mathrm{RH}=$ $100 \%$ ) and at a room temperature. For each type of concrete, the average compressive and flexural tensile strengths were determined at a time period of 7, 14 and 28 days. the three-point bending tensile test is carried out on prismatic specimens with dimensions $(4 \times 4 \times 16 \mathrm{~cm})$ according to NFP18-406 (Fig. 2), the half obtained specimens after the tensile test were tested by the test compression according to EN 196-1 The resulting half-test pieces are therefore fitted between the two plates of the hydraulic press (Fig. 3)

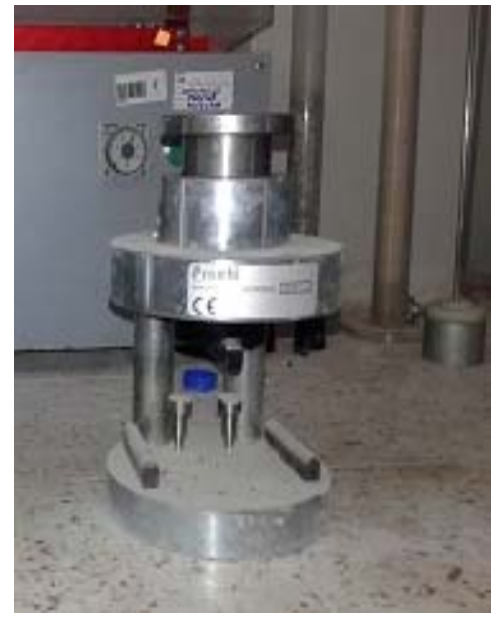

Figure 2: Tensile machine, three point bending test.

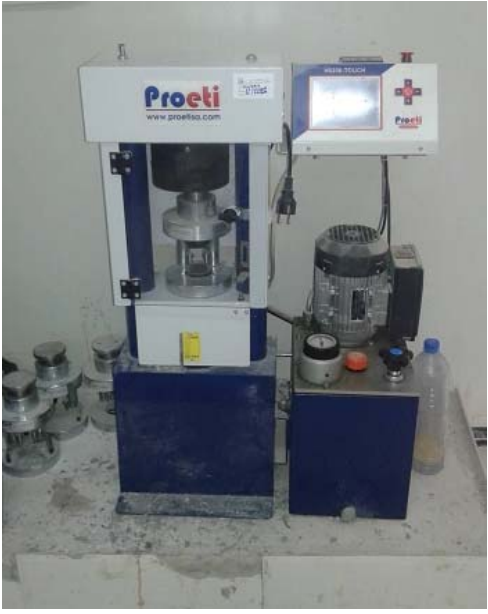

Figure 3: Machine for compresiion test. 


\section{RESULTS AND DISCUSSION}

\section{Effect of varying the dosage of dune sand and quarry sand on the sag test of sand concrete}

7 he results of the influence of the dosage of dune and quarry sand are grouped together in Tab. 6. Fig. 4 shows clearly that the fine sand dosage influences considerably the workability of the concretes tested, for a constant dosage of water and cement and with use of a super plasticizer. Tests show that the richer the sand is in coarse elements (in the case of SC4 and SC5, it becomes more porous and very absorbent, the fineness modulus increases and the more the workability improves, on the other hand the increase in the fin content (case of SC1, SC2) decreases the fineness modulus and results in poorer handling, the Abrams cone sag is of the order of $2 \mathrm{~cm}$ which corresponds to firm concretes. Conversely, for SC3 and SC4 the mixture binary with the same dosage of coarse sand and fine sand or with a high dosage of coarse sand compared to fine sand gave the best maneuverability with subsidence of the order of 5 and $7 \mathrm{~cm}$ (according to the NFP18-451 standard) which reflects the plasticity of the study concrete thanks to the good granulometry of the granular extent. The SC5 is a very plastic concrete. During the test it was noted that before the vibration the water penetrates into the pores (observation of dry concrete) and during the vibration, a film of water is observed on the surface concrete (the water in the pores).

In general, the variation in the workability of sand concretes depends on the dosage of coarse sand, the mineralogical nature and the morphology (surface condition, types and shapes of the pores) of the used sands. Fig. 5 presents an example of workability test carried out by the Abrams' cone on plastic concrete (SC3 and SC4).

\begin{tabular}{cccccc}
\hline Type of Concrete & SC1 & SC2 & SC3 & SC4 & SC5 \\
Sagging $(\mathrm{cm})$ & 2 & 2 & 5 & 7 & 12 \\
\hline
\end{tabular}

Table 6: Evolution of the subsidence value of the 5 types of sand concrete.

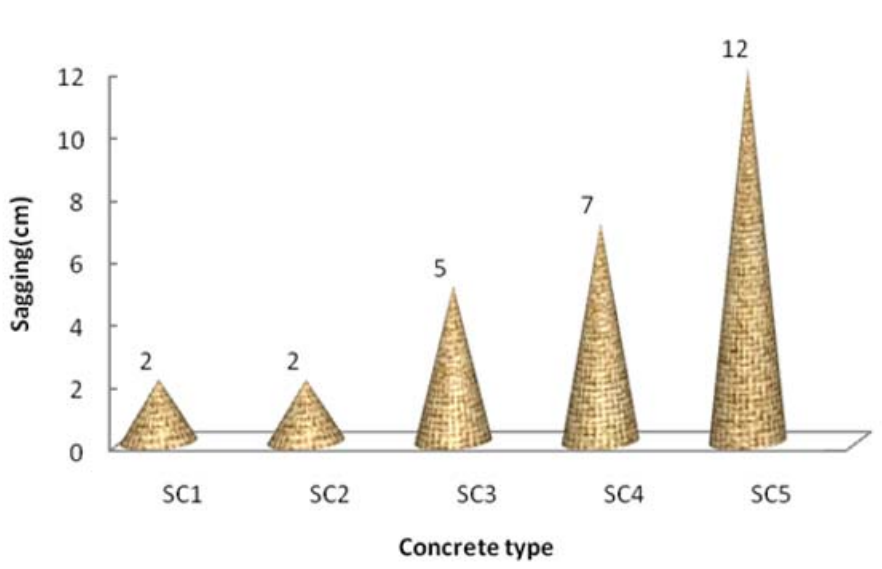

Figure 4: Influence of the dosage of the size of the largest aggragate on the sagging of sand concrete.

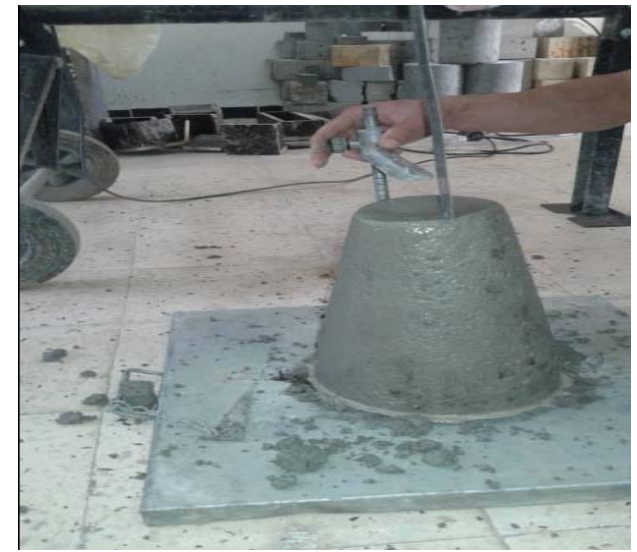

Figure 5: Sagging of plastic concrete (SC3, SC4).

\section{Influence of the dosage of the size of the largest aggregate on the resistance on the mechanical resistance}

Tensile strength by three-point bending (at 7 days, 14 days and 28 days)

Fig. 6 shows that the granulometry, shape and surface condition of aggregates can play an important role in the tensile strength by bending of the studied concrete and that the coarse sand dosage influences the tensile strength by bending. It can be seen that sand is the material which controls the tensile strength for sand concrete, and that increasing the dosage of the size of the larger aggregate has a positive effect on the tensile strength. It is clearly visible in Fig. 6 that, each time the percentage of quarry sand is increased, the tensile strength improves as a function of the age of the concrete for each type of concrete. The lowest three-point flexural tensile strength was recorded at 7 days of time; the minimum is reached by SC1 composed of $100 \%$ dune sand and the maximum was reported by SC3 composed of $50 \%$ DS and $50 \%$ QS, this 
increase is of the order of $26.60 \%$ compared to SC1. For SC4, we noticed a decrease in resistance then it increases again for the SC5 but they always remain slightly lower than that given by the SC3. The rate of increase of SC5 over SC1 is in the order of $21.13 \%$.

At 14 days and 28 days, it was observed that the best strengths are obtained with SC5, which presents the best granular extent with a sheath of the order of $63.88 \%$ and $89.72 \%$ respectively compared to SC1, then the mixture composed of $75 \%$ coarse quarry sand $+25 \%$ fine siliceous sand. The gain in strength compared to SC1 concrete with silica sand is mainly due to the good grain size, the rough surface state and the mineralogical nature of the coarse sand which gives good adhesion between the grains of this sand and the cement matrix and consequently the increase in resistance, which confirms the research results found by $[15,16]$, which showed that the behavior of concrete is influenced by the type of sand, the level of fines and the shape of the particles of the sand. The highest flexural tensile strengths are obtained with quarry sands and the mixture of quarry sand-silica sand.

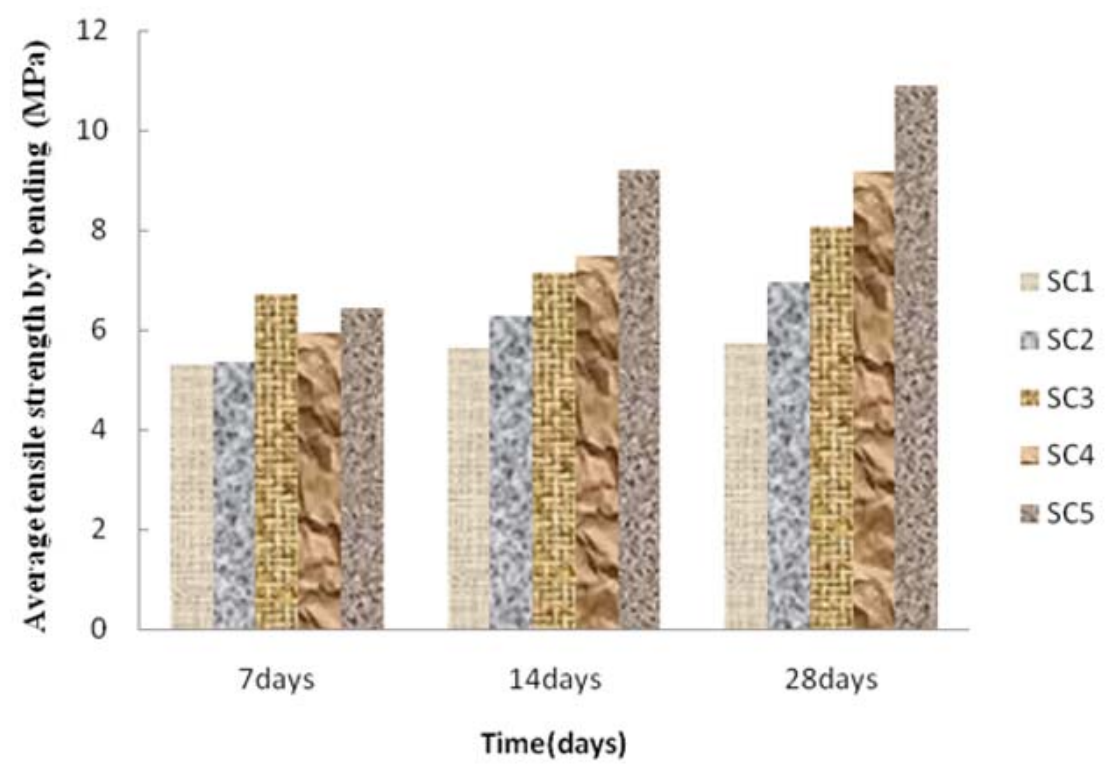

Figure 6: Tensile strength by bending of the study SC at 7 days, 14 days and 28 days.

\section{Compressive strength (at 7 days, 14 days and 28 days)}

The results grouped together in Tab. 7 and illustrated in Fig. 7 show that the size of the largest aggregate has a favorable effect on the compressive strength of the study sand concrete for the various maturities. The best results obtained compared to SC1 are those of SC4 (25\% DS and $75 \%$ QS).

At 7 days, the increase in compressive strength of SC2, SC3, SC4 and SC5 was on the order of $30.43 \%$ and $75.21 \%$ and $90.65 \%$ and $79.78 \%$ respectively. Going from SC4 to SC5, we observed a drop in resistance of around 12\%.

At 14 days, a gain in resistance of SC2, SC3, SC4 and SC5 is to be reported in the order of $4 \%$ and $40.56 \%$ and $71.04 \%$ and $54.19 \%$ respectively. A decrease in resistance is recorded going from SC4 to SC5 of around $23.72 \%$.

The same finding was observed at 28 days, the compressive strength of SC2, SC3, SC4 and SC5 increases by the order of $3.46 \%, 51.54 \%, 80.21 \%$ and $73.53 \%$ respectively. Going from SC4 to SC5, we observed a drop in resistance of around $8.33 \%$.

We can say that to have a good compressive strength, it is necessary to use a large percentage of coarse sand with a small percentage of fine sand. The essential effect of quarry sand is the improvement of the mechanical behavior such as the compressive strength and the addition of a dune sand (which occupies $25 \%$ of the amount of aggregates) has the role of closing the voids and the pores, thus avoiding porosity and achieving good homogeneity and workability for concrete, as well as good compressive strength.

Various researchers $[12,14,15]$ agree that mixing coarse sand with fine sand significantly improves the mechanical behavior of study sand concretes.

It can be concluded that the best results obtained in compression are those with a strong dosage of coarse sand (SC) and other weak of fine sand (SD); one can consider SC4 as an optimal dosage.

The compressive and flexural tensile strength is influenced by the mineralogical nature and the surface condition of the used sands. 


\begin{tabular}{cccc}
\hline & \multicolumn{3}{c}{ Average compressive strength (ACS) } \\
Concrete Type & 7days & 14 days & 28 days \\
& 18.60 & 25.52 & 26.33 \\
SC1 & 24.26 & 26.54 & 27.24 \\
SC2 & 32.59 & 35.87 & 39.90 \\
SC3 & 35.46 & 43.65 & 47.45 \\
SC4 & 33.44 & 39.35 & 45.69 \\
SC5 &
\end{tabular}

Table 7: Average compressive strengths of the study Sand Concrete at 7days, 14 days and 28 days on half of the specimen $(4 \times 4 \times 16) \mathrm{cm}^{3}$.

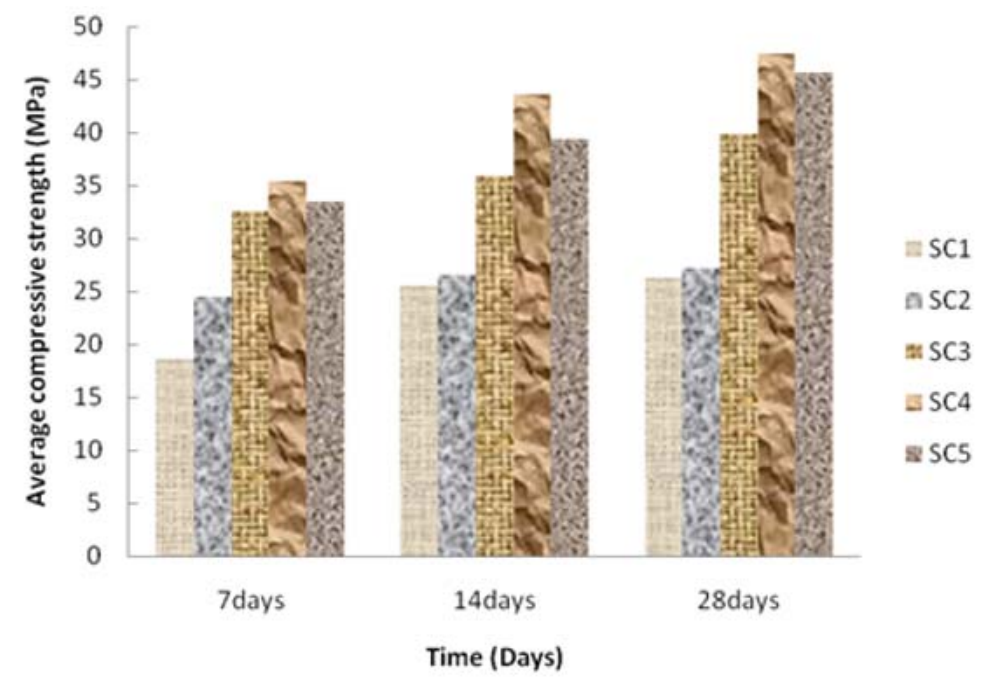

Figure 7: Compressive strength of study SC at 7 days, 14 days and 28 days.

\section{CONCLUSION}

$\mathrm{D}$ ifferent types of concrete are produced in all structures that exist around the world. Each type of concrete has mechanical and physical characteristics depending on their material compositions and formulations.

Sand Concrete has advantages such as improved workability to facilitate the pouring of heavily scrapped elements and in places with difficult access, as well as cost savings (especially in desert countries).Mechanical performances remain one of the most widely used criteria for judging the quality of these concretes and for their classifications. Several studies have been carried out in order to minimize the disadvantages of sand concrete and improve mechanical performance such as correcting the granular extent, adding fibers, etc.

This study has highlighted the influence of the dosage of the size of the largest aggregate on the mechanical behavior of hardened sand concretes while maintaining the rheology in the fresh state necessary for their placement. Sand concrete composed of a high dosage of coarse sand and other weak of fine sand exhibits improvements in compressive strength and sagging which classifies this concrete (SC4) in the range of plastic concrete. The drawn conclusions from the study are the following:

- In a fresh state; the richer the sand in coarse elements, the fineness modulus increases the better the workability improves, on the other hand, increasing the fineness content decreases the fineness modulus and results in poorer handling.

- To ensure great sagging and therefore good workability, it is always necessary to substitute the small aggregate by the large aggregate, the latter forming the granular skeleton of the sand concrete.

- A sand concrete which contains $100 \%$ or $75 \%$ dune sand of the mass of aggregates (SC1 and SC2) is a firm concrete, because of the fineness of the dune sand which contributes to the closing of the pores and voids and also the absorption of mixing water. 
- The use of quarry sand with percentages of $50 \%$ and $75 \%$ of the granular mass have obtained a plastic concrete thanks to the reduction of dune sand which absorbs water and occupies the pores that exist in the body of the concrete. As well as SC5 concrete which contains a percentage of 100\% quarry sand is classified as very plastic concrete based on its slump value $(12 \mathrm{~cm})$.

- In the hardened state; using 100\% and 75\% SDD (case of SC1 and SC2) gave us low compressive and bending tensile strengths when compared to those of SC3, SC4 and SC5.

- The SC4 gave a gain in compressive stress of around 90.69\%; 71.04\% and 80.21\% at different ages 7 days, 14 days and 28 days respectively compared to a control concrete without coarse sand SC1.

- To achieve good compressive strength, it is necessary to ensure good homogeneity of the concrete and it is strongly recommended to use a large percentage of coarse sand with a small percentage of fine sand.

- The increase in the dosage of coarse sand in the composition of sand concretes improves the tensile strength by bending, optimization is achieved for a SC5 composed only of quarry sand. The rate of increase of SC5 over SC1 over 7 days, 14 days and 28 days is of the order of $21.13 \%, 63.88 \%$ and $89.72 \%$ respectively over SC1.

According to the findings, we can conclude that the optimization of the study sand concretes is ensured by the SC4 because it offers to the new sand concrete not only an improvement of the mechanical behavior (tension by bending and compression) but also a plastic grade sand concrete $\mathrm{P}$.

\section{NOMENCLATURE}

SC: Sand Concrete

SD: Sand Dune

QS: Quarry Sand

SC1: Sand Concrete type 1

SC2: Sand Concrete type 2

SC3: Sand Concrete type 3

SC4: Sand Concrete type 4

SC5: Sand Concrete type 5

\section{REFERENCES}

[1] Tavana Amlashi, A., Alidoust, P., Pazhouhi, M., Pourrostami Niavol, K., Khabiri, S., \& Ghanizadeh, A. R. (2021). AIbased formulation for mechanical and workability properties of eco-friendly concrete made by waste foundry sand. Journal of Materials in Civil Engineering, 33(4), 04021038. DOI: 10.1061/(ASCE)MT.1943-5533.0003645

[2] Sablocrete, bétons de sable. (1994). Caractéristiques et pratiques d'utilisation. Presses de l'école nationale des ponts et chaussées (France), $230 \mathrm{p}$.

[3] Melais, G. F. Z., Melais, S., Achoura, D., \& Jauberthie, R. (2015). Valorisation des sous-produits de hauts fourneaux dans la fabrication de une nouvelle gamme de béton de sable (Valorisation of underproducts of blast furnaces in the manufacture of a new sandcrete range). J. Mater. Environ. Sci, 6(3), pp. 735-742.

[4] Mani, M., Bouali, M. F., Kriker, A., \& Hima, A. (2021). Experimental characterization of a new sustainable sand concrete in an aggressive environment. Frattura ed Integrità Strutturale, 15(55), pp. 50-64. DOI: $10.3221 /$ IGF-ESIS.55.04

[5] Melais, S., \& Bouali, M. F. (2020). Experimental Study of Flexural Tensile Strength of Sand Concrete Plates Reinforced with Metallic Fibers. In Key Engineering Materials, 857, pp. 74-82. Trans Tech Publications Ltd. DOI: 10.4028/www.scientific.net/KEM.857.74

[6] L'vovich, K. I. (2004). The sand concrete is a Russian construction material for the XXI century. Construction Materials, the Equipment and Technologies of XXI Century, Russia, 61(2), pp. 16-19.

[7] Bédérina, M., Khenfer, M. M., Dheilly, R. M., \& Quéneudec, M. (2005). Reuse of local sand: effect of limestone filler proportion on the rheological and mechanical properties of different sand concretes. Cement and concrete research, 35(6), pp. 1172-1179. DOI: 10.1016/j.cemconres.2004.07.006 
[8] Guettala, A., Mezghiche, B., \& Chebili, R. (1999). Strength comparisons between rolled sand concrete and dune sand concrete. In Concrete Durability and Repair Technology: Proceedings of the International Conference Held at the University of Dundee, Scotland, UK on 8-10 September 1999 (p. 55). Thomas Telford.

[9] El Euch Khay, S., Neji, J., \& Loulizi, A. (2010). Compacted Sand Concrete in Pavement Construction: An Economical and Environmental Solution. ACI Materials Journal, 107(2).

[10] Khay, S. E. E., Neji, J., \& Loulizi, A. (2010). Shrinkage properties of compacted sand concrete used in pavements. Construction and Building Materials, 24(9), pp. 1790-1795.

[11] Benaissa, A., Kamen, A., Chouicha, K., \& Malab, S. (2008). Panneau 3D au béton de sable. Materials and structures, 41(8), pp. 1377-1391. DOI: 10.1617/s11527-007-9336-8

[12] Rmili, A., Ouezdou, M. B., Added, M., \& Ghorbel, E. (2009). Incorporation of crushed sands and Tunisian Desert Sands in the composition of selfcompacting concretes part II: SCC fresh and hardened states characteristics. International Journal of Concrete Structures and Materials, 3(1), pp. 11-14. DOI: 10.4334/IJCSM.2009.3.1.011

[13] Bederina, M., Makhloufi, Z., Bounoua, A., Bouziani, T., \& Quéneudec, M. (2013). Effect of partial and total replacement of siliceous river sand with limestone crushed sand on the durability of mortars exposed to chemical solutions. Construction and Building Materials, 47, pp. 146-158. DOI: 10.1016/j.conbuildmat.2013.05.037

[14] Balapgol, B., Kulkarni, S. A., \& Bajoria, K. M. (2002, August). Strength and durability of concrete with crushed sand. In 27th Conf. Our World Concr. Struct, pp. 29-30.

[15] Melais, F. Z. (2016). Durabilité des bétons de sable fibres dans les différents milieux agressifs - effets de la nature des fines d'ajouts et fibres, Doctoral dissertation, Université Badji Mokhtar, Annaba.

[16] Khouadjia, M. L. K., Mezghiche, B., \& Drissi, M. (2015). Experimental evaluation of workability and compressive strength of concrete with several local sand and mineral additions. Construction and Building Materials, 98, pp. 194203.

[17] Reddy, T. S. S., \& Dadapeer, A. B. S. (2018). An Experimental Analysis on the Effects of Manufactured Sand on the Compressive Strength of Concrete. International Journal of Scientific Research in Science and Technology (IJSRST), 4(2), pp. 54-60. 